\title{
Escin Increases the Survival Rate of LPS- Induced Septic Mice Through Inhibition of HMGB1 Release from Macrophages
}

\author{
Yajun Cheng ${ }^{a}$ Hongrui Wang ${ }^{b}$ Min Mao Chao Liang ${ }^{c}$ Yu Zhang ${ }^{c}$ Deijun Yang ${ }^{c}$ \\ Ziran Weic Shunxiang Gao ${ }^{d}$ Bo Hu ${ }^{d}$ Lianghua Wang ${ }^{d}$ Qingping Caic \\ aDepartment of General Surgery, Changhai Hospital, Second Military Medical University, Shanghai, \\ 'Department of Orthopedic Surgery, Changzheng Hospital, Second Military Medical University, \\ Shanghai, 'Department of General Surgery, Changzheng Hospital, Second Military Medical University, \\ Shanghai, dDepartment of Biochemistry and Molecular Biology, Second Military Medical University, \\ Shanghai, China
}

\section{Key Words}

Escin • High motility group box 1(HMGB1) • Sepsis $・ N F-\kappa B$

\begin{abstract}
Background: Previous studies have described the effects of Escin on improving the survival rate of endotoxemic animals. The purpose of this study was to explore the molecular mechanisms of this potentially beneficial treatment. Methods: First, the survival rate of endotoxemic mice was monitored for up to 2 weeks after Escin pretreatment, Escin post-treatment, or Escin post-treatment + rHMGB1. The effects of Escin on the release of pro-inflammatory cytokines such as TNF- $\alpha$, IL-1 $\beta$, IL- 6 and HMGB1 in the serum of endotoxemic mice and LPS-induced macrophages were evaluated by ELISA. Furthermore, the mRNA and protein levels of HMGB1 in LPS-induced macrophages were measured by qRT-PCR and Western blot, respectively. Additionally, the release of pro-inflammatory cytokines such as TNF- $\alpha, I L-1 \beta$, IL- 6 was evaluated by ELISA in rHMGB1-induced macrophages. Finally, the protein levels and the activity of NF-KB in macrophages were checked by Western blot and ELISA, respectively. Results: Both pretreatment and post-treatment with Escin could improve the survival rate of endotoxemic mice, while exogenous rHMGB1 reversed this effect. In addition, Escin decreased the level of the pro-inflammatory cytokinesTNF- $\alpha, I L-1 \beta$, IL- 6 and HMGB1 in endotoxemic mice and in LPS-induced macrophages. Escin could also inhibit the mRNA levels and activity of HMGB1. The release of the pro-inflammatory cytokinesTNF- $\alpha, I L-1 \beta$, IL- 6 could be suppressed in rHMGB1-induced macrophages by Escin. Finally, Escin could suppress the activation of NFKB in LPS-induced macrophages. Conclusion: Escin could improve the survival of mice with LPS-induced endotoxemia. This effect maybe meditated by reducing the release of HMGB1, resulting in the suppression of the release of pro-inflammatory cytokines.
\end{abstract}

Y. Cheng, H. Wang and M. Mao contributed equally to this work.

Prof. Lianghua Wang,

and Prof. Qingping Cai

KARGER 125
Department of Biochemistry and Molecular Biology, Second Military Medical University, No.800 Xiangyin Road, Shanghai, 200433, (China) and Department of General Surgery, Changzheng Hospital, Second Military Medical University, No.415 Fengyang Road, Shanghai, 200003 (China), E-Mail lhwang@smmu.edu.cn and E-Mail caiqingpingwcwk@163.com 


\section{Cellular Physiology Cell Physiol Biochem 2015;36:1577-1586 \begin{tabular}{ll|l} 
and Biochemistry $\begin{array}{l}\text { DOI. 1159/000430320 } \\
\text { Published online: July 10, 2015 }\end{array}$ & $\begin{array}{l}\text { O 2015 S. Karger AG, Basel } \\
\text { www.karger.com/cpb }\end{array}$ \\
\cline { 2 - 3 }
\end{tabular} \\ Cheng et al.: The Protective Effect of Escin on Sepsis}

\section{Introduction}

Despite extensive research on the pathophysiology of sepsis and the technical advances in the treatment of sepsis, sepsis remains a major public health problem. The mortality due to this condition remains very high, and it is the second leading cause of death in the intensive care unit (ICU) [1].The pathogenesis of sepsis is characterized by overwhelming inflammatory and immune responses that can lead tissue damage, multiple organ failure and death. Large clinical trials have shown current therapies designed against pro-inflammatory mediators with early and transient kinetics such as tumor necrosis factor-alpha (TNF- $\alpha$ ) and interleukin-1 $\beta(\mathrm{IL}-1 \beta)$ to be ineffective in treating sepsis [2].High mobility group box 1(HMGB1), a late pro-inflammatory mediator, may offer a wider therapeutic window for sepsis [3].Extracellular HMGB1 binds to several cell-surface receptors such as TLR2 or TLR4 in order to activate the production of pro-inflammatory cytokines, chemokines and adhesion molecules by innate immune cells [4]. HMGB1-specific neutralizing antibodies have been shown to rescue mice presenting high levels of systemic HMGB1 from sepsis $[5,6]$.Thus, targeting the pro-inflammatory cytokine HMGB1 may be an ideal therapy for sepsis.

Escin, a natural mixture of triterpenesaponins isolated from AesculusWilsonii Rehd, has been demonstrated to possess anti-inflammatory and anti-edematous effects.Thus, Escin has been extensively used in the clinical treatment of chronic venous insufficiency, hemorrhoids and edema resulting from trauma or operation [7].An increasing number of current and emerging research projects are focused on the anti-inflammatory effects of Escin.For example, Escin has protective effects on endotoxin-induced injury in the liver or the lung by down-regulating levels of pro-inflammatory mediators (TNF- $\alpha$, IL-1 $\beta$, NO, etc.), improving the survival rate $[8,9]$. However, it is not clear whether Escin can influence the expression and release of HMGB1in sepsis. Thus, we used both lipopolysaccharide (LPS)treated macrophages and the mouse model of endotoxemia to investigate the effect of Escin on HMGB1 expression and release.

\section{Method and Materials}

\section{Animals}

A total of 155 Male BALB/c mice (Slaccas Laboratory Inc., Shanghai, China) weighing 20-25 g were housed at $25^{\circ} \mathrm{C}$ and subjected to $12 \mathrm{~h}$ light/dark cycle treatment conditions. All of the animals were fed a standard rodent diet (Slaccas Laboratory Inc.) with access to water ad libitum. All of the animals received humane care in accordance with the recommendations of the Guide for the Care and Use of Laboratory Animals. Approval was obtained from the Institutional Animal Care and Use Committee at the Second Military Medical University (Shanghai, China).

\section{Experimental model}

To evaluate the protective effect of Escin in mice with endotoxemia induced by LPS(15 mg/kg, ip), 25 mice were randomlydivided into five groups(n=5 per group): saline(i.p.); LPS; LPS + Escin(1 mg/kg, i.p.);LPS+Escin(2 mg/kg, i.p.) and LPS+Escin (4 mg/kg, i.p.).Escin(i.p.) was administered $2 \mathrm{~h}$ before LPS injection. Twenty-four hours after LPS treatment, mice were anesthetized with pentobarbital (40 mg/ kg; Sinopharm Chemical Reagent Co., Ltd., Shanghai, China), and blood samples were collected by cardiac puncture andcentrifuged at 12,000 $\times$ g for $30 \mathrm{~min}$. The serum was collected and analyzed for TNF- $\alpha$ andIL-1 $\beta$ by ELISA or for HMGB1 analysis, asdescribed above.

To evaluate the effect of Escin on the survival of endotoxemic with LPS-induced endotoxemia, 60 mice were randomly divided into the following three groups ( $n=20$ per group):LPS +saline (i.p.), LPS+Escin(2 $\mathrm{mg} / \mathrm{kg}$, i.p.) andLPS + Escin( $4 \mathrm{mg} / \mathrm{kg}$, i.p.). The saline or Escin was injected at $2 \mathrm{~h}$ before injection of LPS or at 12,24, 48, 72 and $96 \mathrm{~h}$ after the injection of LPS (15 mg/kg, i.p.). Survival was monitored daily forup to 2 weeks.

To evaluate the effect of delayed Escin injection on the survival of mice with LPS-induced endotoxemia, 40 mice were randomly divided into the following two groups ( $n=20$ per group): LPS+saline(i.p.) andLPS+Escin(4 


\section{Cellular Physiology Cell Physiol Biochem 2015;36:1577-1586 \begin{tabular}{|c|c|}
\hline DOI: 10.1159/000430320 & O 2015 S. Karger AG, Basel
\end{tabular} and Biochemistry $\frac{\text { Published online: July 10, } 2015}{\text { Cheng et al.: The Protective Effect of Escin on Sepsis }}$}

$\mathrm{mg} / \mathrm{kg}$, i.p.). The saline or Escin was injected at 12,24, 48,72 and $96 \mathrm{~h}$ after the injection of LPS(15 mg/kg, i.p.), and animals were similarly monitored for up to 2 weeksto evaluate the survival rate.

To further evaluate the link between HMGB1 and the effect of Escinon the survival rate, 30 mice were randomly divided into three groups ( $\mathrm{n}=10$ per group):LPS + saline (i.p.), $\mathrm{LPS}+\mathrm{Escin}(4 \mathrm{mg} / \mathrm{kg}$, i.p.) $+\mathrm{rHMGB} 1$ (100 $\mu$ g per mouse) and LPS + Escin( $4 \mathrm{mg} / \mathrm{kg}$, i.p.). The saline, Escin or Escin +rHMGB1 were measured at12, 24, 48, 72 and $96 \mathrm{~h}$ after the onset of endotoxemia. Survival was monitored daily for up to 2 weeks.

\section{Materials}

Escin(Sigma-Aldrich, USA) was initially dissolved in dimethyl sulfoxide (DMSO) (Sigma-Aldrich, USA) as a $50 \mathrm{mM}$ stock solution, stored as small aliquots at $-20^{\circ} \mathrm{C}$, and thawed and diluted in cell culture media or normal saline (NS) as required. LPS was purchased from Sigma Aldrich (USA).

\section{Cell culture and stimulation}

The immortalized murine macrophage cell line RAW 246.7 was given as gift from Cao Xuetao's lab. The cells were cultured in RMPI1640 media (Gibco, USA) supplemented with $10 \%$ heat-inactivated fetal calf serum (Gibco, USA) and $100 \mathrm{U} /$ mlpenicillin/streptomycin (Hyclone, China) at $37{ }^{\circ} \mathrm{C}$ in $5 \% \mathrm{CO}_{2}$.

\section{Cell viability}

The RAW 264.7 cells $\left(1 \times 10^{4}\right.$ cells/well $)$ were seeded in 96 -well plates, and cells were treated with various concentrations of Escinor vehicle (normal saline). After $24 \mathrm{~h}$, a Cell Counting Kit-8 (CCK-8) assay kit (Beyotime, China) was used to determinethe viability of the RAW264.7 cells according to the manufacturer's protocol. The experiments were performed in triplicate.

\section{Cell death assay}

After $24 \mathrm{~h}$ of incubation with various concentrations of Escin or vehicle (normal saline), RAW264.7 cells were harvested and lysed for use in the Cell Death Detection ELISAPLUS Assay (Roche Applied Science, Germany) according to the manufacturer's protocol. The cytoplasmic histone-associated DNA fragmentsin vitro (mononucleosomes and oligonucleosomes) generated by apoptotic cell death were quantified through a photometric enzyme immunoassay using mouse monoclonal anti-histone and anti-DNA antibodies. Positive and negativecontrolswere provided by the manufacturer.

Cytokines assay

The levels of TNF- $\alpha, I L-1 \beta$, Interleukin-6 (IL-6) and HMGB1 were measured using commercially available enzyme-linked immunosorbent assay (ELISA) kits from R\&Dsystems(USA) according to the manufacturer's instructions.

\section{Western blot}

Harvested cells were lysed in buffer containing $50 \mathrm{mMTris}-\mathrm{HCl}$ (pH 6.8), 2\%SDS, 10\% glycerol, phosphatase inhibitors $\left(100 \mathrm{mM} \mathrm{Na}_{3} \mathrm{VO}_{4}, 10 \mathrm{mMNaF}\right.$ )and 1 mMprotease inhibitor (phenyl methylsulphonyl fluoride, PMSF) to obtain the whole cell lysates.The insoluble tissue debris was removed by centrifugation at $13,000 \times \mathrm{g}$ at $4{ }^{\circ} \mathrm{C}$ for $15 \mathrm{~min}$. The supernatant was collected and the protein concentration was quantified using a protein assay reagent (BCA, Beyotime, China). The proteins were separated by SDS-PAGE, transferred to a nitrocellulose membrane and incubated with antibodies against HMGB1(Abcam, USA), $\beta$-actin(Santa Cruz Technology, USA), NF- кB-p65 and Histone H3.1(cell Signaling Technology, USA)at $4^{\circ} \mathrm{C}$ overnight. The immunocomplexes were visualized using a horseradish peroxidase-conjugated antibody followed by incubation in a chemiluminescent reagent (Millipore, Billerica, MA, USA) and exposure to a photographic film. The quantification of the Western blot was performed using the Quantity One software.

\section{qRT-PCR}

The total RNA was isolated from frozen tissues and the cells were treated using the TRIzol (TaKaRa, Dalian, China) method. The RNA quality (A260/A280 ratio) and quantity were determined using a standard spectrophotometer. One microgram of total RNA was used for cDNA synthesis using the RevertAidFirst Strand cDNA Synthesis Kit \#1622 (Fermentas, Lithuania) according to the manufacturer's instructions. Appropriate forward and reverse primers were used in the reverse transcriptase polymerase chain reactions 


\section{Cellular Physiology Cell Physiol Biochem 2015;36:1577-1586 \begin{tabular}{l|l|l} 
DOI: 10.1159/000430320 & (C) 2015 S. Karger AG, Basel
\end{tabular} \begin{tabular}{l|l} 
and Biochemistry Published online: July 10, 2015 & www.karger.com/cpb \\
\cline { 1 - 2 }
\end{tabular} \\ Cheng et al.: The Protective Effect of Escin on Sepsis}

(RT-PCRs) for cDNA amplification to detect the transcripts of interest. The primer sequences for $\beta$-actin andHMGB1 have been previously described [10]. The PCR conditions used for the amplification were as follows: $94{ }^{\circ} \mathrm{C}$ for $10 \mathrm{~min}$, then 40 cycles of $94^{\circ} \mathrm{C}$ for $30 \mathrm{~s}, 55-58{ }^{\circ} \mathrm{C}$ for $30 \mathrm{~s}$, and $72{ }^{\circ} \mathrm{C}$ for $45 \mathrm{~s}$, followed by $72{ }^{\circ} \mathrm{C}$ for 10 min. qRT-PCR was conducted using a 7300 Real-time PCR System (Applied Biosystems, USA). Standard curves were plotted for each optimized assay, each of which produced a linear plot of the threshold cycle (Ct) against log (dilution). The amount of each target was quantified based on the concentration obtained from the standard curve and was presented in arbitrary units. The quantity of each target was normalized against the quantity of GAPDH.

\section{Recombinant HMGB1 proteins}

The experimental procedure using recombinant HMGB1 protein has been previously described [11]. Briefly, the full-length coding sequence of human HMGB1 (Genechem, China) was inserted into the pMD 18T Cloning Vector(Genechem, China) and a NheI/Xhol fragmentwas subcloned into the pET-28a vector (Novagen, Madison, WI, USA).Positive clones were selected and confirmed by DNA sequencing. The plasmids were transformed into the protease-deficient E.coli strain BL21 (DE3) pLysE (Novagen) and were induced with0.5 mMisopropyl-D-thiogalactopyranoside (Sigma-Aldrich,USA) for $3 \mathrm{~h}$. TherHMGB1 was purified with a Ni-NTA agarose column (Novagen,USA) and ion-exchange chromatography(GE Healthcare Bio-Sciences AB, USA). The endotoxin was removed by detergent phase separation with TritonX-114 (Sigma-Aldrich,USA).

\section{$N F-\kappa B$ binding assay}

The NF- $\kappa$ B binding assay was performed using the NF- $\kappa \mathrm{B}$ p50/p65 transcription factor assay kit (Millipore, USA) according to the manufacturer's protocol. The absorbance of the samples was measured at $450 \mathrm{~nm}$ using a standard spectrophotometer.

\section{Statistical evaluation}

Survival rates were compared using the Kaplan-Meier log-rank test. Other data were expressed as the means \pm S.E.M. The data were analyzed using one-way ANOVA with the Bonferroni post hoc test for multiplet-tests. A value of $\mathrm{P}<0.05$ was considered to be significant. All data shown are from three independent experiments.

\section{Results}

Escin has a protective effect and improves the survival of endotoxemic animals

Our results showed that Escin pretreatment attenuated the LPS-induced increase of TNF- $\alpha$, IL-1ßand IL-6 levels in serum (Fig. 1). Furthermore, Figure 2A showed that Escin pretreatment ( $4 \mathrm{mg} / \mathrm{kg}$ ) significantly improved the survival rate compared with LPS-treated mice. As some pro-inflammatory cytokines, including TNF- $\alpha, I L-6$ and IL-1 $\beta$, have narrower therapeutic windows and reach their maximum levels within $4 \mathrm{~h}$ [12],delayed Escin injection was used to determine whether Escin can improve the survival rate of endotoxemic animals. Escin injected $12 \mathrm{~h}$ after LPS injection improved the survival rate of endotoxemic animals (Fig. 2B),suggesting that Escin acts on a late pro-inflammatory cytokine but not TNF- $\alpha$, IL-6 or IL-1 $\beta$, which all have narrower therapeutic windows, thereby improving the survival rate of endotoxemic animals.

\section{Escin improves survival in lethal endotoxemia through HMGB1}

Though delayed Escin injection could improve the survival rate of endotoxemic mice, whether this effect was mediated by a specific type of cytokine is unknown. The serum levels of HMGB1,a late pro-inflammation mediator, have been reported to increase in sepsis, and high levels of HMGB1 are positively correlated with the severity of sepsis in animals $[12,13]$.

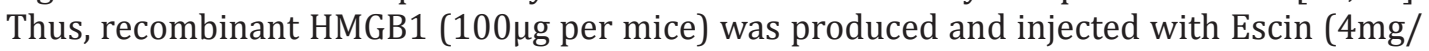
$\mathrm{kg}$ ) into endotoxemic mice $12 \mathrm{~h}$ after LPS injection. The improvement that delayed Escin had on the survival rate of endotoxemic mice could be reversed by rHMGB1 $(\mathrm{p}<0.05)$ (Fig. 3 ). These results suggested that the effects of Escin injection on the release of HMGB1 play a critical role in improving the survival rate of endotoxemic mice. 


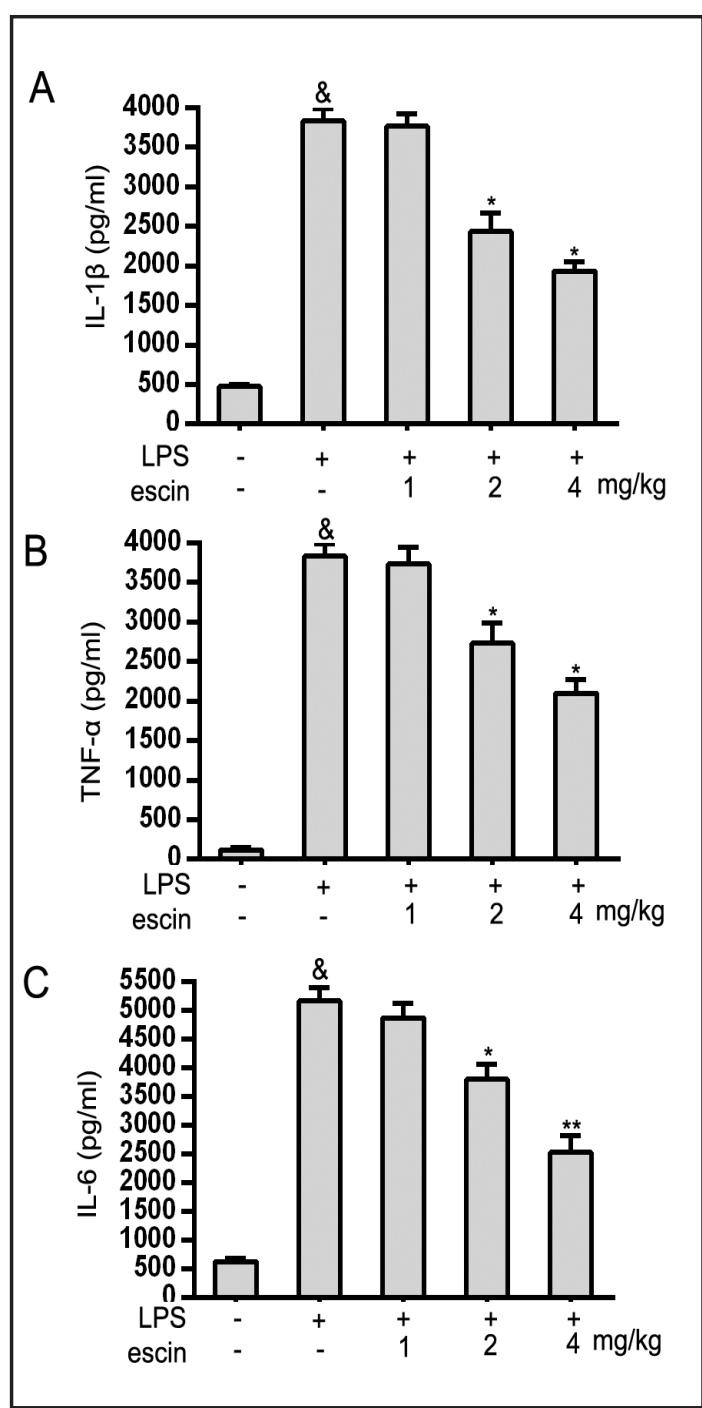

Fig. 1. The effects of Escin on LPS-induced release of cytokines in endotoxemicmice.Serum IL-1 $\beta(A), T-$ NF- $\alpha(B)$ andIL-6(C) levels were examined at $24 \mathrm{~h}$ though ELISA after endotoxemiawas induced in mice by LPS. $(\& P<0.01$, indicating significance compared with the control; ${ }^{*} P<0.05$ or ${ }^{* *} P<0.01$, indicating significance compared with LPS).

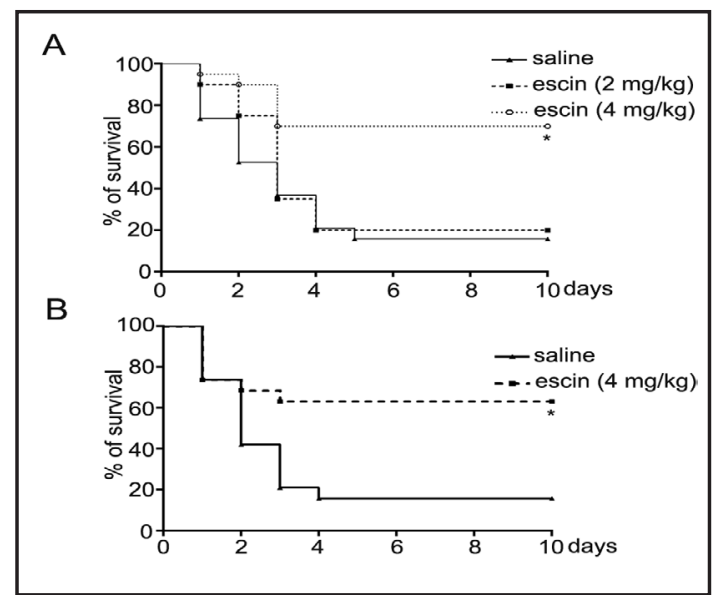

Fig. 2. The effects of Escinon survival rate in endotoxemic animals.(A) Mice were pretreated with saline orEscin ( $2 \mathrm{mg} / \mathrm{kg}$ or $4 \mathrm{mg} / \mathrm{kg}) 2 \mathrm{~h}$ before LPS treatment (15 mg/kg). (B) Mice were subjected to lethal endotoxemia (LPS, $15 \mathrm{mg} / \mathrm{kg}$ ) and were treated with saline or Escin( $4 \mathrm{mg} / \mathrm{kg}$ ) $12 \mathrm{~h}$ later.The significance ofthe differences in survival times was assessed using the Kaplan-Meier test. $\left({ }^{*} P<0.05\right.$, indicating significance compared with saline).

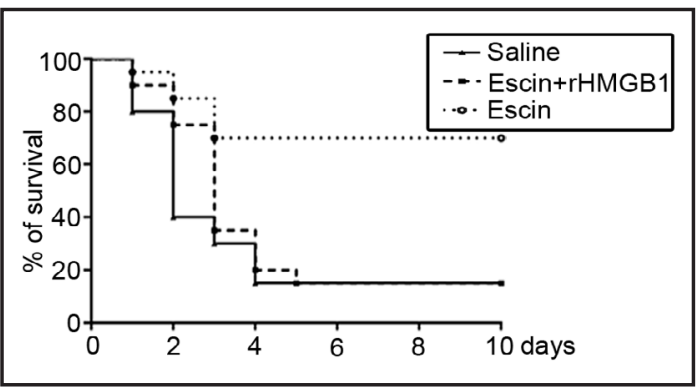

Fig. 3. The link between HMGB1 and the effect of Escin on survival rate.Mice were randomly divided into three groups ( $n=10$ per group):LPS + saline (i.p.), LPS + Escin (4 mg/kg, i.p.)+rHMGB1 (100 $\mu$ g per mouse) and LPS + Escin (4 mg/kg, i.p.). The saline, Escin or Escin +rHMGB1 groups were measured at12, 24, 48, 72 and $96 \mathrm{~h}$ after the onset of endotoxemia. Survival was monitored daily for up to 2 weeks. $\left({ }^{*} P<0.05\right.$, indicating significance compared with saline).

\section{Effects of Escin on the viability and apoptosis of RAW 264.7 cells}

Increasing concentrations of Escin $(0,1,5$ and $10 \mu \mathrm{M})$ were used to study its effects on cell viability (Fig. 4A).The result showed that Escin did not have a significant effect on RAW 264.7 cell viability at concentrations of $1-10 \mu \mathrm{M}$. In addition, one-step sandwich ELISA, which specifically quantifies fragmented DNA released into the cytoplasm, was used to measure cell apoptosis induced by Escin. The results showed that Escin did not have a significant effect on the apoptosis of RAW 264.7 cell safter $24 \mathrm{~h}$ incubation (Fig. 4B). These results suggested that Escin was safe (neither apoptosis-inhibiting nor apoptosis-inducing) to macrophages at concentrations below $10 \mu \mathrm{M}$. 


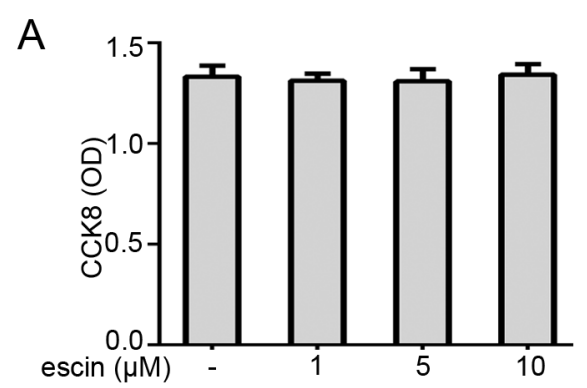

B

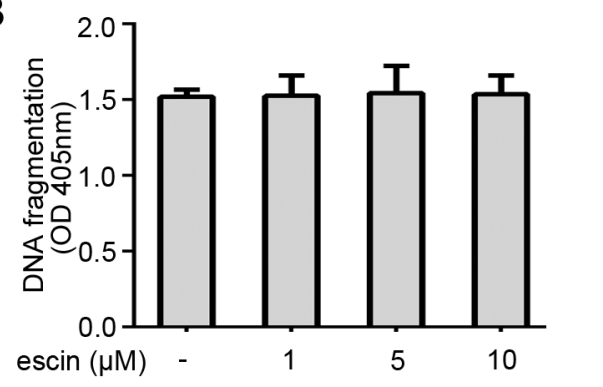

Fig. 4. The effects of Escin on the viability and apoptosis of RAW264.7 cells, which were incubated with graded concentrations of Escin $(0,1,5$ and $10 \mu \mathrm{M})$. (A)Cell viability was measured using a Cell Counting Kit-8 (CCK-8). (B)Apoptosis was measured using a one-step sandwich enzyme-linked immunosorbent assay (ELISA) kit. ( $\mathrm{P}>0.05$, indicating no significance compared with the control).

Escin attenuates the pro-inflammatory response in macrophages exposed to LPS

We showed that the levels of IL-1 $\beta$, TNF- $\alpha$ and IL- 6 in the LPS plus Escin group significantly decreased in a dose-dependent manner in comparison to the LPS group $(p<0.05)$ (Fig. 5). These results suggested that Escin could attenuate the LPS-induced pro-inflammatory response in macrophages.

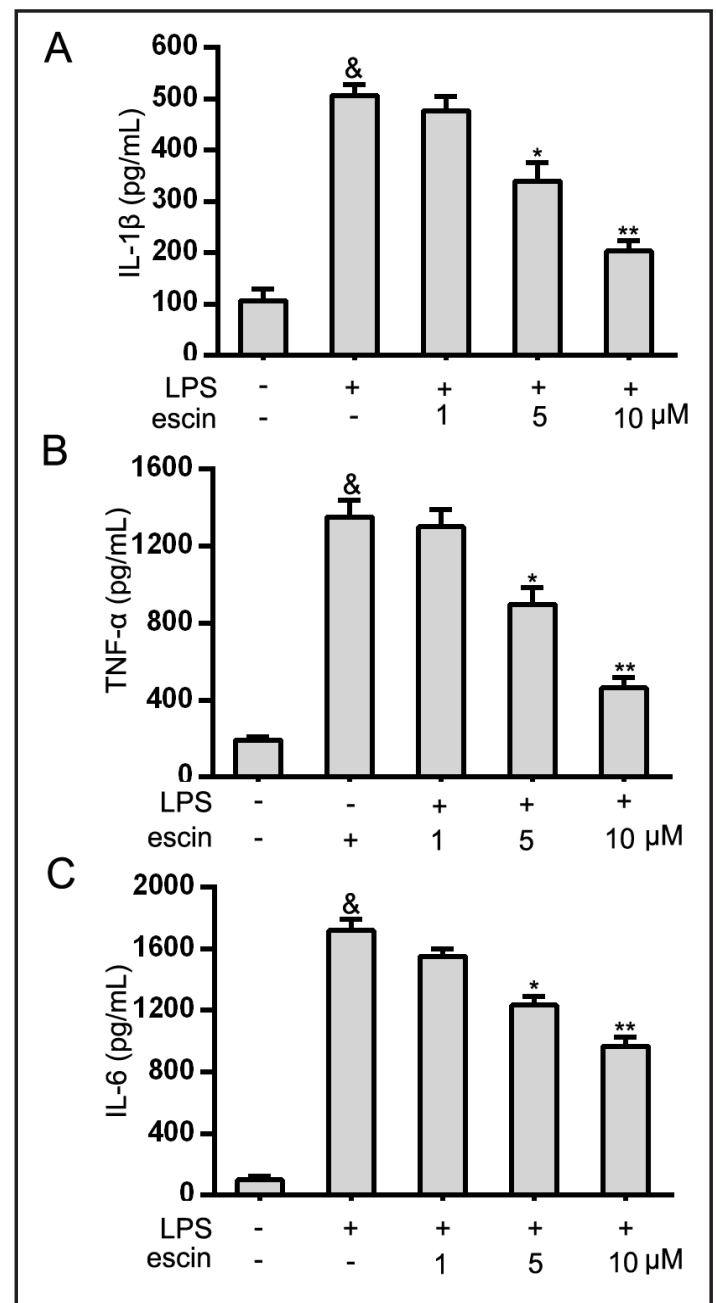

Fig. 5. The release of cytokines in LPS-induced macrophages were influenced by Escin. (A to C) Cells were pretreated with $0,1,5$ and $10 \mu \mathrm{M}$ Escinfor $2 \mathrm{~h}$ and then were stimulated with LPS $(1 \mu \mathrm{g} / \mathrm{ml})$ for $16 \mathrm{~h}$. After incubation, culture media samples were collected and subjected to ELISAs for IL-1 $\beta(A)$, TNF- $\alpha(B)$ and IL- $6(C) .(\& P<0.01$, indicating significance compared with the control; ${ }^{*} P<0.05$ or ${ }^{* *} P<0.01$, indicating significance compared with LPS).

\section{Escin inhibits the LPS-induced expression, nuclear/cytosolic translocation and extracellular release of HMGB1}

When macrophages were stimulated by exogenous bacterial products or proinflammatory cytokines, the intranuclear protein HMGB1 translocated from the nucleus into the cytoplasm and was subsequently released extracellularly. Extracellular HMGB1 plays a critical role in the developmentof sepsis [12]. Thus, we investigated whether Escin could affect the LPS-induced extracellular levels of HMGB1. Fig. 6 A and B suggested that Escin inhibited the cytosolic translocation of HMGB1 from the nucleus and subsequently attenuated the extracellular levels of LSP-induced HMGB1in macrophages. In addition, we found that Escin could inhibit the LPS-induced increase in HMGB1 mRNA expression in macrophages (Fig. 6C). These results suggested that Escin might act as anappropriate inhibitor of LPS-induced HMGB1in macrophages. 


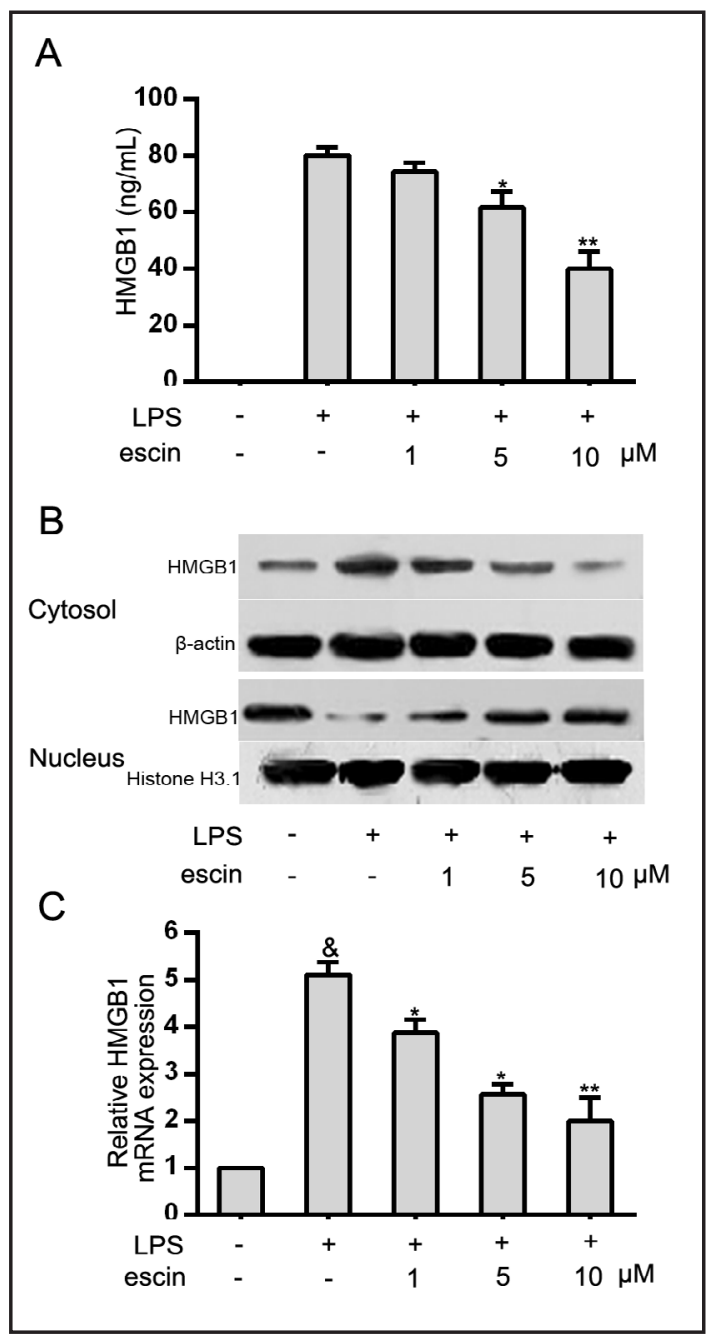

Fig. 6. The effects of Escinon HMGB1 release and mRNA expression in LPS-induced macrophages. (A to C) Cells were pretreated with 0, 1, 5 and $10 \mu \mathrm{M}$ Escinfor $2 \mathrm{~h}$ and then were stimulated with LPS $(1 \mu \mathrm{g} /$ $\mathrm{ml}$ ) for another $24 \mathrm{~h}$. (A) Culture media sampleswere collected and subjected to ELISA for HMGB1. (B) Cells were collected and subjected to nuclear/cytosol fractionationand immunoblottingagainst HMGB1 as described inthe Methods.(C) Total RNA was extracted and assayed for HMGB1 mRNA by quantitativereal-time polymerase chain reaction (qRT-PCR). $\left({ }^{*} P<0.01\right.$, indicating significance compared with the control; ${ }^{*} P<0.05$ or ${ }^{* *} P<0.01$, indicating significance compared with LPS).

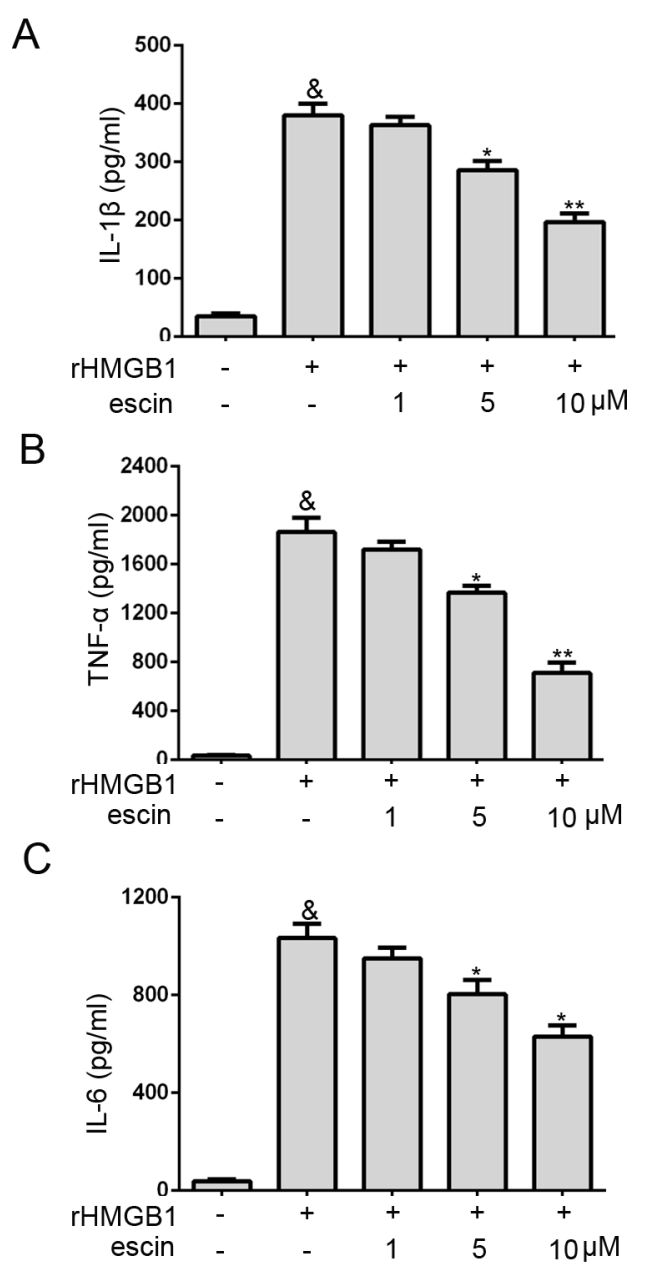

Fig. 7. The effects of Escin on the release of pro-inflammatory cytokines in rHMGB1-induced macrophages. (A to C) Cells were pretreated with 0,1,5 and $10 \mu \mathrm{M}$ Escin for $2 \mathrm{~h}$ and were then stimulated with rHMGB1 (500 ng/ml) for another $4 \mathrm{~h}$. After incubation, culture media samples were collected and subjected to ELISAs for IL-1 $\beta(A)$, TNF- $\alpha(B)$ and IL-6(C). $(\& P<0.01$, indicating significance compared with control; $* P<0.05$ or ${ }^{* *} P<0.01$, indicating significance compared with rHMGB1).

Escin inhibits the release of pro-inflammatory cytokines in rHMGB1-induced macrophages

As a pro-inflammatory cytokine, HMGB1 released from activated monocytes and macrophages could activate macrophages to stimulate the release of various proinflammatory cytokines, such as IL- $1 \beta$ and TNF- $\alpha$ [14].Thus, we investigated whether Escin could affect the levels of pro-inflammatory cytokines in rHMGB1-induced macrophages. As shown in Fig. 7A-C, after $4 \mathrm{~h}$ of macrophage stimulation with rhHMGB1 (500 ng/ml), various pro-inflammatory cytokines including IL-1 $\beta$, TNF- $\alpha$ and IL- 6 were detected in the 
Fig. 8. Escin reduces the activity of the nuclear factor nuclear factor-kappa B (NF- $\kappa$ B) in a dose-dependent manner.(A and B) RAW264.7 cells were pretreated with $\operatorname{Escin}(1,5$, and $10 \mu \mathrm{M})$ for $2 \mathrm{~h}$ and stimulated with LPS for $30 \mathrm{~min}$. (A)The nuclear translocation of $\mathrm{p}-65$, a componentof the NF- $\mathrm{B}$ signaling pathway, was determined via Western blot of the extracted nuclear proteins. (B)NF- $\mathrm{B}$ activity was further verified using the NF- $\mathrm{BB}$ p50/p65 transcription factor assay kit. $(\& \mathrm{P}<0.01$, indicating significance compared with the control; ${ }^{*} \mathrm{P}<0.05$ or ${ }^{* *} \mathrm{P}<0.01$, indicating significance compared with LPS).

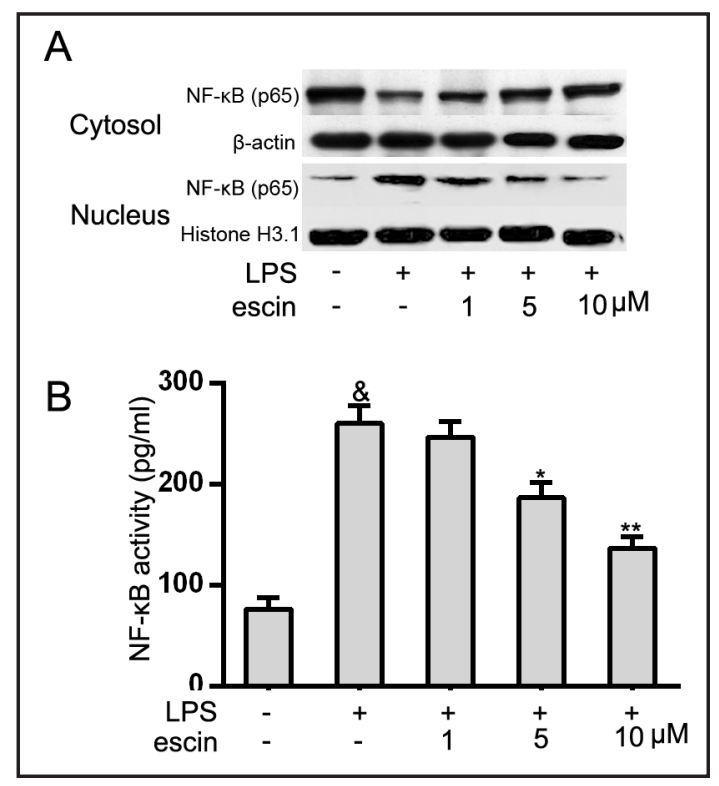

culture media. The levels of these cytokines, which were induced by rHMGB1, were reduced after Escin pretreatment in a dose-dependent manner. These results suggested that Escin can suppress the release of pro-inflammatory cytokines caused by rHMGB1 stimulation of macrophages.

LPS-induced NF- $\kappa B$ activation suppressed by Escin may participate in mediating the expression and release of HMGB1

The expression and release of HMGB1 is closely correlated with the NF- $\kappa \mathrm{B}$ pathway, which is constitutively activated in sepsis or in LPS-induced macrophages [15].To investigate the molecular mechanism of Escin-mediated inhibition of HMGB1, the activation of NF- $\mathrm{KB}$ was examined by Western blot and an NF- $\kappa \mathrm{B}$ binding assay. Fig. $8 \mathrm{~A}$ showed that pretreatment with Escin prevented LPS-induced p65 nuclear localization. Meanwhile, Escin treatment reduced NF- $\mathrm{kB}$ activity significantly in a dose-dependent manner (Fig. 8B). These results suggested that the activation of NF- $\mathrm{KB}$ in LPS-induced macrophages might be suppressed by Escin.

\section{Discussion}

Escin is the predominantly active constituent of triterpenesaponins isolated from AesculusWilsoniiRehd and has been demonstrated to possess anti-edematous and anti-inflammatory effects. Recently, it was found that Escin attenuated acute lung and liver injury and decreased the mortality rate induced in septic mice $[8,9]$, though its mechanisms of action remained unknown. In the present study, we demonstrated that Escin increases the survival rate of LPS-induced septic mice potentially through inhibiting the release of HMGB1 from macrophages. Additionally, suppression of LPS-induced NF- $\kappa B$ activation by Escin may participate in mediating the expression and release of HMGB1.

The prevailing theories of sepsis as an uncontrolled systemic inflammatory response are supported by extensive studies employing various animal models of sepsis [12]. Multiple organ dysfunction syndrome induced by excessive systemic inflammation insepsis is the most common cause of death in intensive care units [9].In response to systemic infection, innate immune cells such as macrophages release large amounts of pro-inflammatory meditators that determine the outcome of systemic inflammation [12].Here, we found that Escin treatment significantly inhibited TNF- $\alpha$, IL-1 $\beta$ and IL- 6 production in LPS-stimulated RAW 264.7 cells, a murine macrophage cell line. TNF- $\alpha$ and IL-1 $\beta$ are critical cytokines KARGER 


\section{Cellular Physiology Cell Physiol Biochem 2015;36:1577-1586

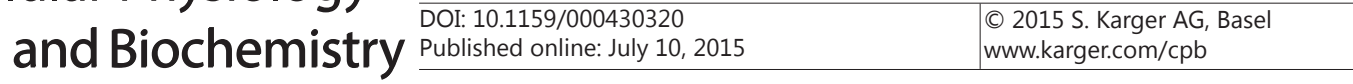 \\ Cheng et al.: The Protective Effect of Escin on Sepsis}

in the inflammatory network that play key roles in the induction and perpetuation of inflammation by up-regulating other pro-inflammatory cytokines such as IL-6 [16]. Therapy with neutralizing antibodies against TNF- $\alpha$ increasedthe survival rates in an animal model ofendotoxemic/bacteremic shock [14]. However, serum TNF- $\alpha$ and IL-1ßreached toxic levels in mice and human volunteers within 1-2 $\mathrm{h}$ after LPS administration [17].Thus, delayed treatments that target the early kinetics of systemic pro-inflammatory cytokines such as TNF- $\alpha$ and IL- $1 \beta$ are always ineffective in a clinical setting [13].The investigation of other late pro-inflammatory mediators (such as HMGB1) as potential therapeutic targets for the clinical treatment of sepsis is therefore considered to be urgent.

HMGB1, a DNA-binding protein, was recently recognized to act as a potent proinflammatory cytokine during infection responses. Some reports support the significance of HMGB1 in playing a critical pathological role in severe sepsis. The serum levels of HMGB1 have been shown to first increase after infection and subsequently increase to plateau levels from 16 to $32 \mathrm{~h}$, and high serum levels of HMGB1 are correlated with the severity and lethality of sepsis in animals $[12,13]$. High serum levels of HMGB1have also been found in septic patients, indicating a higher lethality caused by sepsis [18]. In addition, the administration of exogenous HMGB1 to experimental animals has led to the enhancement of severe inflammatory responses, tissue injury and death, whereas HMGB1-specific neutralizing antibodies conferred a dose-dependent protection against lethal endotoxemia and increased the survival rate of endotoxemic mice $[19,20]$. Consistent with our results, innate immune cells have been shown to be activated by extracellularHMGB1, which acts as a chemokine or cytokine to activate macrophage to produce pro-inflammatory cytokines, such as TNF- $\alpha$, IL-1 $\beta$ and IL-6 [15 , 21].Altogether, these data establish extracellular HMGB1as a critical late mediator of sepsis. Thus, HMGB1 may be a potential target for the treatment of sepsis.

The present study showed that Escin inhibited the endotoxin-induced release of HMGB1 in vitro and in vivo. Furthermore, exogenous HMGB1 reversed the effects of Escin in decreasing lethality in endotoxemic animals whereas the release of pro-inflammatory cytokines in rHMGB1-induced macrophages was suppressed by Escin.These data indicated that the inhibition of HMGB1 release played an important role in Escin's protective mechanisms for sepsis. It is possible that Escin inhibits the release of TNF- $\alpha$ and IL- $1 \beta$ in order to meditate the release of HMGB1 from LPS-activated macrophages in endotoxic mice [22]. In addition, the inhibition of NF- $\kappa$ B activation by Escin in LPS-activated macrophages may be another possible mechanism for its inhibitory effect on the release of HMGB1 [23].

In summary, we evaluated the therapeutic effects of Escin in LPS-induced sepsis and explored its potential mechanism. Our results demonstrated that Escin could inhibit the release of the pro-inflammatory cytokines TNF- $\alpha$,IL-1 $\beta$, IL- 6 and HMGB1, which may provide a new protective mechanism in sepsis. In addition, Escin could also improve the survive rate of mice treated with LPS, an effect that is potentially meditated by reducing the release of HMGB1. Finally, the suppression of NF- $\kappa$ B activation in LPS-induced macrophages by Escin may help to mediate the expression and release of HMGB1.

\section{Acknowledgement}

This study is supported by National high-tech Reasearch and Development Program of China (2013AA092904).

\section{Disclosure Statement}

The authors do not have any possible conficts of interest.

\section{References}

1 Liesenfeld O, Lehman L, Hunfeld KP, Kost G: Molecular diagnosis of sepsis: New aspects and recent developments. Eur J MicrobiolImmunol (Bp) 2014;4:1-25. 


\section{Cellular Physiology Cell Physiol Biochem 2015;36:1577-1586 \begin{tabular}{l|l|l}
\hline DOI: 10.1159/000430320 & C 2015 S. Karger AG, Basel
\end{tabular} www.karger.com/cpb \\ Cheng et al.: The Protective Effect of Escin on Sepsis}

2 Lotze MT, Tracey KJ: High-mobility group box 1 protein (HMGB1): nuclear weapon in the immune arsenal. Nat Rev Immunol 2005;5:331-342.

3 Huang W, Tang Y, Li L: HMGB1, a potent proinflammatory cytokine in sepsis Cytokine 2010;51:119-126.

4 Yang Y, Li S, Yang Q, Shi Y, Zheng M, Liu Y, Chen F, Song G, Xu H, Wan T, He J, Chen Z: Resveratrol reduces the proinflammatory effects and lipopolysaccharide- induced expression of HMGB1 and TLR4 in RAW264.7 cells. Cell Physiol Biochem 2014;33:1283-1292.

5 Wang H, Bloom O, Zhang M, Vishnubhakat JM, Ombrellino M, Che J, Frazier A,Yang H, Ivanova S, Borovikova L, Manogue KR, Faist E, Abraham E, AnderssonJ,Andersson U, Molina PE, Abumrad NN, Sama A, Tracey KJ: HMGB-1 as a late mediator of endotoxin lethality in mice.Science 1999;285:248-251.

6 Yang H, Ochani M, Li J, Qiang X, Tanovic M, Harris HE, Susarla SM, Ulloa L, Wang H, DiRaimo R, Czura CJ, Wang H, Roth J, Warren HS, Fink MP, Fenton MJ, Andersson U, Tracey KJ: Reversing established sepsis with antagonists of endogenous high-mobility group box 1. ProcNatlAcadSci U S A 2004;101:296-301.

7 Sirtori CR: A Escin: pharmacology, pharmacokinetics and therapeutic profile. Pharmacol Res 2001;44:183193.

8 Xin W, Zhang L, Fan H, Jiang N, Wang T, Fu F: Escin attenuates acute lung injury induced by endotoxin in mice. Eur J Pharm Sci 2011;42:73-80.

9 Jiang N, Xin W, Wang T, Zhang L, Fan H, Du Y, Li C, Fu F: Protective effect of Escin from the seeds of Aesculushippocastanum on liver injury induced by endotoxin in mice. Phytomedicine 2011;18:1276-1284.

10 Zhang Z, Zhang L, Zhou C, Wu H: Ketamine inhibits LPS-induced HGMB1 release in vitro and in vivo. IntImmunopharmacol 2014;23:14-26.

11 Liu T, He YW: Protective effect of recombinant HMGB1 A box protein in mouse with acute hepatic failure. ZhonghuaGanZang Bing ZaZhi 2010;18:222-226.

12 Li Y, Gan CP, Zhang S, Zhou XK, Li XF, Wei YQ, Yang JL, Wu M: FIP200 is involved in murine pseudomonas infection by regulating HMGB1 intracellular translocation. Cell Physiol Biochem 2014;33:1733-1744.

13 Huston JM, Wang H, Ochani M, Ochani K, Rosas-Ballina M, Gallowitsch-Puerta M, Ashok M, Yang L, Tracey KJ, Yang H: Splenectomy protects against sepsis lethalityand reduces serum HMGB1 levels. J Immunol 2008;181:3535-3539.

14 O'Riordain MG, O'Riordain DS, Molloy RG, Mannick JA, Rodrick ML: Dosage and timing of anti-TNF-alpha antibody treatment determine its effect of resistance to sepsis after injury. J Surg Res 1996;64:95-101.

15 Wu ZS, Yao YM, Hong GL, Xu XP, Liu Y, Dong N, Zheng JY, Lu ZQ Zhao GJ, Zhu XM, Zhang QH, Sheng ZY: Role of mitofusin-2 in high mobility group box-1 protein-mediated apoptosis of T cells in vitro. Cell Physiol Biochem 2014;33:769-783.

16 Kanczkowski W, Chatzigeorgiou A, Samus M, Tran N, Zacharowski K, ChavakisT, Bornstein SR: Characterization of the LPS-induced inflammation of the adrenal gland in mice. Mol Cell Endocrinol 2013;371:228-235.

17 Huang W, Tang Y, Li L: HMGB1, a potent proinflammatory cytokine in sepsis. Cytokine 2010;51:119-126.

18 Gámez-Díaz LY, Enriquez LE, Matute JD, Velásquez S, Gómez ID, Toro F, OspinaS, Bedoya V, Arango CM, Valencia ML, De La Rosa G, Gómez CI, García A, PatiñoPJ,Jaimes FA: Diagnostic accuracy of HMGB-1, sTREM-1, and CD64 as markers of sepsis in patients recently admitted to the emergency department. AcadEmerg Med 2011;18:807-815.

19 Wang H, Bloom O, Zhang M, Vishnubhakat JM, Ombrellino M, Che J, Frazier A,Yang H, Ivanova S, Borovikova L, Manogue KR, Faist E, Abraham E, Andersson J,Andersson U, Molina PE, Abumrad NN, Sama A, Tracey KJ: HMG-1 as a late mediator of endotoxinlethality in mice. Science 1999;285: 248-251.

20 Sama AE, D'Amore J, Ward MF, Chen G, Wang H: Bench to bedside: HMGB1-a novel proinflammatory cytokine and potential therapeutic target for septic patients in the emergency department. AcadEmerg Med 2004;11: 867-873.

21 Harris HE, Raucci A: Alarmin (g) news about danger. EMBO Reports 2006;7:774-778.

22 Jiang W, Pisetsky DS: The role of IFN-alpha and nitric oxide in the release of HMGB1 by RAW264.7 cells stimulated with polyinosinic-polycytidylic acid or lipopolysaccharide. J Immunol 2006;177: 3337-3343.

23 Bonaldi T, Talamo F, Scaffidi P, Ferrera D, Porto A, Bachi A, Rubartelli A, Agresti A, Bianchi ME: Monocytic cells hyperacetylate chromatin protein HMGB1to redirect it towards secretion. EMBO J 2003;22: 55515560. 